\title{
Pengaruh Keterampilan Interpersonal, Pengalaman Kerja, Integritas dan Keterikatan Kerja terhadap Kinerja Penyuluh Pertanian
}

\author{
Didit Darmawan, Rahayu Mardikaningsih* \\ Fakultas Ekonomi, Manajemen, Universitas Mayjen Sungkono, Mojokerto, Indonesia \\ Email: 1dr.diditdarmawan@ gmail.com, ${ }^{2}$ rahayumardikaningsih@ gmail.com \\ Email Penulis Korespondensi: rahayumardikaningsih@gmail.com \\ Submitted: 22/11/2021; Accepted: 29/11/2021; Published: 30/11/2021
}

\begin{abstract}
Abstrak-Penyuluh Pertanian merupakan petugas dinas pertanian yang bertugas membantu petani menjalankan usaha tani melalui sistem penyuluhan sebagai bentuk kegiatan belajar bagi petani dan pengusaha pertanian agar dapat membantu dan mengorganisir diri saat mencari dan menggunakan informasi mengenai pasar, pemodalan, teknologi, dan sumber daya yang lain untuk mampu mengembangkan efisiensi usaha, produktivitas, kesejahteraan dan pendapatan, serta perkembangan tingkat kesadaran untuk melestarikan lingkungan. Penyuluh pertanian harus memiliki kompetensi teknis dan manajerial karena penyuluh pertanian harus memiliki kemampuan teknis yang berkaitan dengan pertanian, dan kapabilitas manajerial meliputi kemampuan mengelola pekerjaan untuk melaksanakan penyuluhan. Untuk melakukan kegiatan penyuluhan diperlukan penyuluh yang berkualitas. Kinerja penyuluh menentukan efektivitas kegiatan penyuluhan sehingga diperlukan faktor-faktor penentu dari kinerja penyuluh. Penelitian ini melibatkan satu variabel terikat serta empat variabel bebas alat analisis regresi linier berganda. Penelitian yang dilakukan di Kabupaten Lumajang, Jawa Timur. Penelitian ini menghasilkan empat temuan yaitu: (1) keterampilan interpersonal berperan signifikan pada kinerja; (2) kinerja penyuluh tidak dipengaruhi signifikan oleh pengalaman kerja; (3) integritas memiliki dampak yang signifikan pada kinerja penyuluh; (4) naik turunnya kinerja penyuluh mendapatkan peran dari keterikatan kerja.
\end{abstract}

Kata Kunci: Keterampilan Interpersonal; Pengalaman Kerja; Integritas; Keterikatan Kerja; Kinerja Penyuluh

Abstract-Agricultural Extension Officers are agricultural service officers who are tasked with helping farmers run farming businesses through an extension system as a form of learning activity for farmers and agricultural entrepreneurs so that they can help and organize themselves when looking for and using information about markets, capital, technology, and other resources to be able to developing business efficiency, productivity, welfare and income, as well as developing the level of awareness to preserve the environment. Agricultural instructors must have managerial and technical competencies because agricultural instructors must have technical capabilities related to agriculture, and managerial capabilities include the ability to manage work to carry out extension services. To carry out outreach activities, qualified instructors are needed. The performance of the extension agent determines the effectiveness of the extension activity so that it is necessary to determine the determinants of the performance of the extension worker. The research was conducted in Lumajang Regency, East Java. This study resulted in four findings, namely: (1) interpersonal skills have a significant role in performance; (2) the performance of the instructor is not significantly affected by work experience; (3) integrity has a significant impact on the performance of extension workers; (4) the ups and downs of the performance of the extension worker get the role of work engagement.

Keywords: Interpersonal Skills; Work Experience; Integrity; Work Engagement; Instructor Performance

\section{PENDAHULUAN}

Sektor pertanian adalah sektor utama yang berperan terhadap perekonomian di Indonesia. Pertumbuhannya harus berkelanjutan dan upaya pengembangannya dengan meningkatkan produksi pertanian dan pendapatan petani melalui olah modal, olah keterampilan dan olah lingkungan sehingga produktivitas dan pemberdayaan tercapai bersama (Darmawan, 2018; 2021). Sektor pertanian tetap memiliki potensi menjanjikan di masa mendatang sehingga perhatian dan pengembangan harus terus dilakukan terhadap para petani.

Para petani senior yang memasuki usia tua memiliki ilmu dasar bertani namun pola pikir mereka untuk melakukan kegiatan pertanian berpedoman dari pengalaman dan kebanyakan masih bernuansa tradisional. Para petani usia muda adalah generasi penting mengembangkan sektor pertanian (Van den Ban et al., 1996). Mereka harus diedukasi seiring perkembangan teknologi dan ilmu pertanian. Keterlibatan teknologi di sektor pertanian memerlukan tindakan yang kooperatif, inovatif dan kreatif agar prinsip-prinsip pertanian terlaksana dengan baik (Didiza, 2005). Tindakan penyuluhan pertanian yang dilaksanakan secara terus-menerus tentu akan memberikan manfaat untuk para petani dan keluarganya karena akan memperoleh informasi teknologi yang mendukung (Suvedi et al., 1999). Keberadaan penyuluhan diharapkan memunculkan kemandirian bagi petani untuk mengembangkan diri tentang cara bertani yang efektif memperoleh hasil panen dan pendapatan yang optimal (Mardikaningsih, 2019).

Keberhasilan program penyuluhan bergantung pada kemampuan yang dimiliki sumber daya manusia yang ikut terlibat (Hariani, 2017). Sumber daya manusia dari pihak petani yang bersedia untuk menerima pengetahuan dan informasi dari para penyuluh, dan dari pihak penyuluh yang memiliki kemampuan sesuai kebutuhan para petani. Para penyuluh menjadi pihak pertama yang berhubungan dengan petani dan sebagai penyampai program dinas pertanian kepada masyarakat (Weiss et al., 2000). Mereka harus dibekali dengan beragam kompetensi untuk menjamin keberhasilan program tersampaikan. Kompetensi personil menentukan pencapaian tujuan organisasi (Arifin et al., 2019; Sinambela et al., 2020). Masyarakat layak untuk menerima kinerja terbaik dari aparatur negara (Sjamsi dan Darmawan. 2004). Dalam hal ini petugas penyuluh. Kinerja penyuluh ditentukan beberapa faktor seperti keterampilan interpersonal, pengalaman kerja, integritas dan keterikatan kerja. 
Keterampilan interpersonal diperlukan untuk mencapai efektivitas penyuluhan kepada petani melalui komunikasi dan interaksi yang harmonis. Hal ini sering terjadi pada saat sosialisasi program maupun pemantauan yang dilakukan penyuluh. Kompetensi penyuluh memiliki ciri khas seperti bentuk empati dan keterampilan interpersonal membantu kesulitan atau apa yang dibutuhkan orang lain (Benson, 2014; Darmawan et al., 2018). Menurut Sato et al. (2019), keberhasilan menerapkan keterampilan interpersonal akan memberikan pengaruh bersifat positif terhadap peningkatan kinerja seseorang dalam konteks organisasi. Ketrampilan interpersonal menunjukkan kualitas seseorang. Kualitas sumber daya manusia menentukan kinerja yang dapat diberikan kepada organisasi (Darmawan, et al., 2020).

Pengalaman kerja berperan penting membentuk kinerja seseorang. Penyuluh sebagai pelaksana lapangan yang memiliki pengalaman berkualitas dan memiliki kematangan diri akan lebih baik dalam menyikapi sesuatu hal berkaitan pekerjaan dibandingkan mereka yang tidak memiliki pengalaman (Gibson et al., 2011). Pengalaman berkualitas diartikan sebagai sikap berkesinambungan untuk melakukan pekerjaan dan menyelesaikan tanggung jawab sesuai dengan ketentuan dan standar kerja (Valero, 2016; Darmawan et al., 2020). Dalam kehidupan seharihari, pengalaman diasumsikan terlihat dari usia seseorang dikarenakan seiring bertambahnya usia maka pengetahuan dan kedewasaan seseorang semakin baik dan hal tersebut seharusnya menjadi faktor penunjang utama dari melaksanakan kewajiban (Andayani et al., 2010; Hariani et al., 2019). Pengetahuan seseorang tentang pekerjaan akan semakin meningkatkan sejalan dengan bertambahnya usia serta presepsi terhadap suatu masalah akan lebih bijak. (Valero, 2016). Penyuluh yang memiliki masa kerja lebih lama menjadi perhatian dan panutan bagi yang lebih yunior (Palembeta dan Arifin, 2014). Perilaku mereka teramati dan pada umumnya mereka diharapkan memberikan saran berdasarkan pengalaman dan pengetahuannya (Mardikaningsih, 2014; Arifin et al., 2017). Penyuluh yang memiliki pengalaman seharusnya memiliki kinerja yang layak dijadikan tolok ukur bagi mereka yang belum memiliki pengalaman (Darmawan, 2017). Sebuah studi menunjukkan bahwa pengalaman berperan yang signifikan pada kinerja seseorang (Kotur dan Anbazhagan, 2014).

Penyuluh juga harus memiliki integritas. Integritas merupakan faktor utama dari profesi dan perilaku kerja berdasarkan kejujuran dan kesadaran (Becker, 1998). Kepekaan sosial dalam interaksi ditunjukkan dengan adanya konsisten ucapan dan tindakan serta kesesuaian antara komitmen organisasi (Simons, 2002; Palanski dan Yammarino, 2009; Werdati et al., 2020). Peran sebagai komunikator maupun mediator program menempatkan penyuluh pada posisi panutan dan pihak yang layak menjadi sumber informasi bagi para petani (Bitzer, 2016; Mardikaningsih et al., 2017). Hal ini menjadi beban bagi penyuluh untuk tetap konsisten antara ucapan dan tindakan. Integritas menjadikan seseorang memiliki peran pemimpin dan individu yang teramati di lingkungan kerja (Santosa dan Darmawan. 2002; Martin et al. 2013). Karakter integritas yang melekat pada penyuluh akan memunculkan kepercayaan para petani sebagai target program (Luthans, 2007; Hutomo, 2011). Di organisasi, integritas diperlukan untuk menjaga profesionalisme sebagai penyuluh (Putra et al., 2019). Dengan integritas akan ada keselarasan antara komitmen organisasi dengan praktek yang dilakukan para penyuluh di lapangan. Adanya integritas akan memengaruhi kinerja penyuluh. Hal ini seperti ditunjukkan pada studi empiris yang diteliti oleh Guchait et al. (2016) menyimpulkan kinerja karyawan dipengaruhi signifikan oleh integritas.

Setiap penyuluh harus merasakan adanya keterikatan kerja karena hal tersebut mampu memberikan pengaruh yang signifikan terhadap keberhasilan organisasi. Ketika seseorang merasa terikat dengan pekerjaannya, mereka termotivasi untuk memberikan kinerja terbaik dan memiliki komitmen pribadi untuk mencapai tujuan organisasi (Wahyudi et al., 2006; Bakker dan Leiter, 2010). Seseorang dengan keterikatan terhadap pekerjaan akan meningkatkan produktivitasnya pada organisasi (Robbins dan Judge 2008; Putra et al., 2017). Menurut Schaufeli dan Bakker (2001), seseorang yang memiliki keterikatan kerja ditandai dengan semangat, dedikasi, dan totalitas Seseorang dengan keterikatan kerja akan memiliki dedikasi tinggi dan tanggung jawab pekerjaan yang diperlukan untuk mencapai tingkat keterlibatan kerja yang tinggi (Dubinsky et al. 1986). Pekerjaan sebagai penyuluh mempunyai keterlibatan kerja yan cukup tinggi dan berkomunikasi dengan para petani sehingga aspek-aspek sosial dan pribadi diperlukan untuk menunjang hasil kerja yang diharapkan organisasi (Khasanah et al., 2010; Karina et al., 2012). Studi sebelumnya membuktikan naik turunnya kinerja pegawai merupakan dampak signifikan dari keterikatan kerja. (Christian et al., 2011).

Penyuluh sebagai kontributor keberhasilan program organisasi harus memberikan kinerja melalui tenaga dan kemampuan kerja. Meski demikian menurut Daft (2003), kinerja bukanlah konsekuensi atau hasil dari tindakan melainkan tindakan itu sendiri. Empat variabel yang telah diuraikan sebelumnya, yaitu keterampilan interpersonal, pengalaman kerja, integritas dan keterikatan kerja, di penelitian ini akan dikaji pengaruhnya terhadap kinerja penyuluh pertanian. Dengan demikian tujuan penelitian ini adalah mengetahui dan melakukan analisisi tentang dampak darri keterampilan interpersonal, pengalaman kerja, integritas dan keterikatan kerja pada kinerja penyuluh pertanian.

\section{METODE PENELITIAN}

Studi ini merupakan penelitian kuantitatif dan eksplanatori karena bermaksud membuktikan hubungan pada variabel yang sedang diteliti dengan uji hipotesis. Populasi adalah aparat penyuluh berjumlah 139 orang yang berada di Kabupaten Lumajang. Aparat penyuluh terbagi menjadi tiga bagian uaitu penyuluh pertanian ahli yang berjumlah 38 
orang, yang kedua merupakan kelompok penyuluh pertanian terampil sebanyak 41 orang, dan kelompok selanjutnya merupakan THL - TB PP sebanyak 61 orang. Seluruh kelompok penyuluh tersebut tersebar di 21 kecamatan. Penelitian ini menggunakan teknik pengambilan sampel dilakukan dengan cara mengambil minimal dua penyuluh di masing-masing kecamatan dan hal itu menggunakan purposive sampling sebagai metodenya. Total sampel yang dilibatkan adalah 42 penyuluh.

Studi ini melibatkan satu variabel terikat dengan empat variabel bebas. Variabel terikat kinerja penyuluh terdiri dari enam indikator yaitu kualitas kerja; produktivitas; pengetahuan pekerjaan; kehandalan; kehadiran; dan kemandirian (Dessler, 2013). Variabel bebas keterampilan interpersonal (X.1) memiliki lima dimensi yaitu kemampuan menyelesaikan konflik, kemampuan inisiatif, kemampuan untuk dukungan emosional, kemampuan untuk bersifat terbuka, kemampuan bersifat asertif (Buhrmester et al., 1988). Variabel bebas pengalaman kerja (X.2) terdiri dari empat indikator yaitu konflik peran; ambiguitas peran; dukungan pengawasan; dan keterlibatan kerja (Babin dan Boles, 1996). Variabel integritas (X.3) terdiri dari empat indikator yaitu prediktor kinerja pekerjaan; penentu perilaku kontraproduktif; penentu utama kepercayaan; efektivitas relevan dengan keberhasilan organisasi (Becker, 1998). Variabel bebas keterikatan kerja (X.4) diukur melalui tiga indikator yaitu vigor sebagai wujud dari kekuatan mental dan juga kekuatan fisik ketika melakukan tugas; dedication yang menggambarkan emosional terhadap pekerjaannya; absorption yang ditunjukkan pada perilaku penyuluh dengan memberikan fokus yang baik dan sungguh-sungguh pada setiap penyelesaian tugasnya (Schaufeli dan Bakker, 2001).

Kuesioner disusun berdasarkan skala Likert dengan rentang nilai 1-8 (Sangat Tidak Setuju Sekali=1, Sangat Tidak Setuju=2, Tidak Setuju=3, Kurang Setuju=4, Cukup Setuju=5, Setuju=6, Sangat Setuju=7, Sangat Setuju sekali=8). Teknik analisis pada studi ini liniear berganda yang akan mengukur empat variabel bebas dan akan dihubungkan dengan satu variabel terikat. Untuk menguji kualitas data terkumpul dari responden maka dilakukan uji reliabilitas disertai juga dengan uji kelayakan pada model regresi yang akan dirumuskan dengan menggunakan uji asumsi klasik

\section{HASIL DAN PEMBAHASAN}

Uji validitas dilakukan untuk mengukur instrumen pada kadar kejujuran dan sesuai dengan variabel penelitian (Pallant 2011). Batasan 0,3 ke atas untuk factor loading yang lebih besar dai nilai 0,3 maka telah mencapai nilai minimum tetapi disarankan untuk menggunakan batas nilai $\pm 0,4$. Jika nilai mencapai di atas 0,5 ,aka item pernyataan dinyatakan sangat oenting untuk melakukan intrepetasi konstruk pengukuran (Hair et al., 2010). Berdasarkan hasil SPSS didapatkan hasil pernyataan melalu kuesioner penelitian factor loading lebih dari 0,3 .

Uji reliabilitas ditujukan untuk mengukur kehandalan dalam arti hasil yang konsisten dengan nilai yang sama (Chakrabartty, 2013). Besar tingkat andal (reliabilitas) Cronbach's Alpha yang ideal adalah minimal 0,6 (Hair et al., 2010). Di program SPSS terlihat dari nilai Cronbach Alpha > 0,6 sehingga dapat dikatakan andal. Tabel 1 menunjukkan hasil output SPSS.

Tabel 1. Uji Reliabilitas

\begin{tabular}{ccc}
\hline Variabel Penelitian & Cronbach's alpha & Status \\
\hline Keterampilan Interpersonal (X.1) & 0,668 & Reliabel \\
Pengalaman Kerja (X.2) & 0,612 & Reliabel \\
Integritas (X.3) & 0,704 & Reliabel \\
Keterikatan Kerja (X.4) & 0,714 & Reliabel \\
Kinerja Penyuluh (Y) & 0,659 & Reliabel \\
\hline
\end{tabular}

Sumber: output SPSS

Hasil yang ditunjukkan Tabel 1 diartikan bahwa variabel penelitian menghasilkan nilai sebesar 0,6 ke atas sehingga variabel penelitian dapat dinyatakan reliabel. Selanjutnya melakukan tes asumsi klasik. Untuk yang pertama dilakukan tes normalitas untuk mengetahui sebaran data pada model regresi residual berdistribusi normal. Tes normalitas dilakukan dengan melakukan riset pada normal P-P Plot yang dilakukan dengan cara mengamati data yang berada di sekitar sumbu diagonal pada grafik. Data yang berada disekitar dan menyebar pada garis diagonal. Hasil ini membuktukan regresi pada penelitian ini normal. Seperti yang terlihat pada gambar 1, data penelitan tersebar disekitar garis diagonal. Hasil ini menunjukkan data yang diperoleh pada penelitian ini berdistribusi normal.

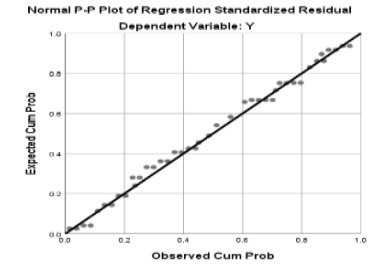

Gambar 1. Uji Normalitas Sumber: output SPSS 
Pengamatan grafik juga dilakukan pada uji heterokedastisitas. Gambar 2 menyajikan hasil data yang tidak berpola jelas. Titik pada sumbu y menyebar merata dan tidak terjadi bentuk pola tertentu. Dengan demikian membuktikan penelitian tidak mengalami heteroskedastisitas.

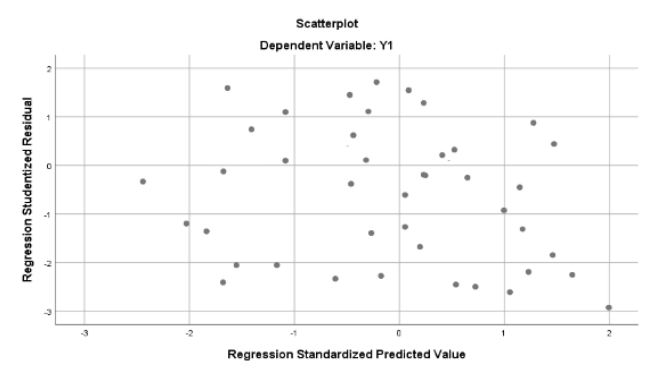

Gambar 2. Uji Heteroskedastisitas Sumber: output SPSS

Tes autokorelasi penelitian ini menggunakan batasan nilai dari Durbin Watson (DW). Nilai Durbin Watson seperti ditunjukkan pada Tabel 4 adalah 1,634, yang berarti nilai yang diperoleh berada kurang dari dua dan lebih dari negative dua sehingga tidak terdapat permasalahan pada uji autokorelasi. Uji multikolinearitas diamati dari nilai toleransi dan nilai VIF. Hasil output SPSS masing-masing nilai VIF kurang dari 10 serta hasil dari tolerance memiliki nilai tidak lebih dari 1 sehingga model penelitian tidak dapat dikatakan memiliki karakteristik multikolinearitas.

Tabel 2. Uji t

\begin{tabular}{|c|c|c|c|c|c|c|}
\hline & \multirow[b]{2}{*}{ Model } & \multicolumn{2}{|c|}{ Unstandardized Coefficients } & \multirow{2}{*}{$\begin{array}{c}\text { Standardized } \\
\text { Coefficients }\end{array}$} & \multirow[b]{2}{*}{$\mathrm{t}$} & \multirow[b]{2}{*}{ Sig. } \\
\hline & & $\mathrm{B}$ & Std. Error & & & \\
\hline 1 & (Constant) & 1.583 & 2.297 & & .689 & .495 \\
\hline & X.1 & .453 & .189 & .247 & 2.401 & .022 \\
\hline & X.2 & .367 & .283 & .146 & 1.300 & .202 \\
\hline & X.3 & 1.873 & .228 & .678 & 8.211 & .000 \\
\hline & $\mathrm{X} .4$ & .416 & .194 & .235 & 2.356 & .046 \\
\hline
\end{tabular}

Sumber: output SPSS

Penelitian dapat dilanjutkan dengan uji hipotesis sebab telah memenuhi uji asumsi klasik dengan menggunakan alat tes $t$ untuk mengetahui beran dari variabel bebas yang digunakan pada variabel terikat. Hasil dari uji t didapatkan dengan cara melihat besaran probabilitas sig untuk masing-masing variabel idependen yang menggunakan dasar 0,05. Berdasarkan nilai yang didapatkan nilai P Sig. yang disajikan Tabel 2 didapatkan hasil 0,022 untuk variabel bebas keterampilan interpersonal; 0,202 untuk variabel pengalaman kerja; nilai 0,000 untuk variabel integritas; dan didapatkan hasil 0,001 untuk variabel keterikatan kerja. Tiga variabel bebas berdampak signifikan pada variabel kinerja penyuluh karena nilainya berada di bawah batas 0,05 . Sementara itu, kinerja penyuluh tidak mendapatkan peran yang signifikan dari pengalaman kerja karena memiliki nilai $\mathrm{P}$ signifikan di atas 0,05 . Meski demikian pada hasil tes $\mathrm{F}$ yang berguna untuk melihat besarnya peran variabel bebas untuk memberikan pengaruh pada variabel terikat secara bersama didapatkan peran signifikan karena nilai P. Signifikan di bawah nilai 0,05 seperti ditunjukkan pada Tabel 3.

Tabel 3. Uji F

\begin{tabular}{llrrrrr}
\hline Model & Sum of Squares & df & Mean Square & F & Sig. \\
\hline 1 & Regression & 268.555 & 4 & 67.139 & 35.097 & $.000^{\mathrm{b}}$ \\
& Residual & 70.778 & 37 & 1.913 & & \\
& Total & 339.333 & 41 & & & \\
\hline
\end{tabular}

Sumber: output SPSS

Koefisien determinan 0,769 menandakan model regresi berganda ini yang variabel bebasnya terdiri dari keterampilan interpersonal (X.1), pengalaman kerja (X.2), integritas (X.3) dan keterikatan kerja (X.4) telah memberikan dampak sebesar $76,9 \%$ pada naik turunyakinerja penyuluh sedangkan $23,1 \%$ merupakan peran variabel lain sebagai sisanya.

Tabel 4. Koefesien Determinasi

\begin{tabular}{|c|c|c|c|c|c|}
\hline Model & $\mathrm{R}$ & R Square & Adjusted R Square & $\begin{array}{l}\text { 1. Error of the } \\
\text { Estimate }\end{array}$ & Durbin-Watson \\
\hline 1 & $.890^{\mathrm{a}}$ & .791 & .769 & 1.38308 & 1.634 \\
\hline
\end{tabular}

Di penelitian ini ditemukan keterampilan interpersonal memiliki peran signifikan pada kinerja penyuluh. Hasil ini menjadi hasil memperkuat temuan dari Syahrudin (2018) dan Sato et al. (2019) yang menyatakan bahwa keterampilan 
interpersonal secara keseluruhan dianggap sebagai hal yang kritis bagi keberhasilan kinerja individu. Menurut Singh (2014), dengan keterampilan interpersonal, seseorang dapat melakukan proses penyampaian informasi secara baik dan mamu memiliki kesamaan pemahaman pada semua orang. Seorang penyuluh yang memiliki keterampilan interpersonal mendalam dapat dengan mudah membantu bergaul dengan para petani, menghilangkan persepsi yang saling bertentangan, membangun hubungan yang dapat dipercaya, dan berfungsi sebagai partisipan atau anggota tim yang produktif. Penyuluh mampu berinteraksi dengan petani dan mampu menjalin hubungan baik karena keterampilannya dalam berkomunikasi maupun bersosialisasi dengan masyarakat (Mardikaningsih, 2016). Kondisi ini menjelaskan bahwa keterampilan interpersonal yang dimiliki penyuluh pertanian berperan secara signifikan pada kinerja penyuluh (Mardikaningsih, 2019).

Temuan kedua adalah pengalaman kerja pada studi ini tidak memberikan dampak signifikan pada kinerja penyuluh. Temuan ini tidak sejalan dengan hasil yang dikemukakan Kotur dan Anbazhagan, (2014) dan Darmawan et al. (2019) yang menjelaskan kinerja individu dipengaruhi signifikan oleh pengalaman kerja. Masa kerja dari para penyuluh dan latar belakang pendidikan mereka kemungkinan memiliki relevansi (Paloniemi, 2006). Adanya penguatan dari latar belakang pendidikan memungkinkan hasil tersebut diperoleh tidak signifikan berpengaruh seperti yang dinyatakan oleh Nusbuga (2009) yang menyatakan bahwa komposisi dari pendidikan dan pengalaman kerja saling menguatkan untuk menghasilkan kinerja individu yang lebih baik. Menurut Roos et al. (2001) untuk memaksimalkan potensi seseorang dapat dilakukan dengan meningkatkan kompetensi mereka dan mengolahnya sehingga batasan kecerdasan intelektual dapat terdeteksi sesuai dengan tugas atau tanggung jawabnya.

Temuan ketiga dari penelitian ini adalah integritas memiliki peran signifikan pada kinerja penyuluh dan memperkuat penelitian dari Guchait et al. (2016). Penyuluh dengan integritas yang baik menghasilkan kinerja yang baik pula (Marchus dan Schuler, 2004). Untuk memperkuat integritas para penyuluh dapat dilakukan dengan mengindentifikasi kepuasan kerja dan tingkat komitmen organisasi (Sinambela, 2014; Bitzer, 2016). Kepuasan kerja dan komitmen organisasi yang baik akan memperkuat integritas para penyuluh sehingga mampu memproduksi kinerja yang sesuai dengan harapan organisasi (Djati, 2005).

Temuan berikutnya di penelitian ini adalah keterikatan kerja memiliki dampak signifikan pada naik turunnya kinerja penyuluh dan temuan ini memperkuat penelitian dari Christian et al. (2011). Para penyuluh memiliki kewajiban memberikan hasil kerja terbaik untuk membantu tercapainya tujuan organisasi (Darmawan et al., 2018). Penyuluh harus pula memberikan komitmen, loyalitas, dan kinerja (Rhoades dan Eisenberger, 2002; Darmawan et al., 2020). Selain itu para penyuluh diharuskan untuk lebih berperan kerja aktif saat bekerjal; menginvestasikan energi pribadi untuk pekerjaan yang dilakukan serta memiliki hubungan emosional yang terjaga dengan pekerjaan (Furiady, 2015). Keterikatan kerja memunculkan ikatan secara psikologis pada segala bentuk pekerjaan yang dilakukan sertamemberikan keyakinan pada diri seseorang tentang kemampuannya saat mengerjakan tugas. Dari pihak organisasi harus selalu secara konsisten melakukan upaya peningkatan kapasitas dan kapabilitas para penyuluh.

\section{KESIMPULAN}

Penelitian ini menghasilkan empat temuan yaitu: (1) keterampilan interpersonal berdampak signifikan pada kinerja penyuluh; (2) kinerja penyuluh tidak dipengaruhi oleh pengalaman kerja; (3) integritas memiliki peran signifikan pada naik turunnya kinerja penyuluh; (4) keterikatan kerja mempunyai peran yang signifikan pada kinerja penyuluh. Dari temuan tersebut disarankan beberapa hal sebagai berikut. Organisasi harus selalu memerhatikan dan meningkatkan kapasitas dan kapabilitas penyuluh. Keterampilan interpersonal pada setiap diri dari penyuluh perlu dikembangkan lagi agar mampu menciptakan manusia yang handal dan berkualitas. Harapan tersebut dapat diwujudkan melalui upaya pengembangan berupa pelatihan softskill secara berkesinambungan. Pengalaman kerja akan memberikan kontribusi berarti bila setiap penyuluh melakukan kewajibannya dengan bersungguh-sungguh, memiliki komitmen yang tinggi dan terus mengembangkan kompetensi dengan melibatkan diri dengan berbagai masalah untuk berperan menyelesaikannya sehingga pembelajaran di lapangan kerja dapat memberikan makna berarti seiring waktu dan bertambahnya masa kerja. Integritas dapat diperkuat dengan upaya memberikan hasil kerja terbaik dari para penyuluh serta menjunjung tinggi kejujuran dan nilai-nilai moral karena berhubungan langsung dengan masyarakat. Mereka harurs membangun hubungan dan interaksi yang harmonis, mampu mengorganisasikan diri sendiri, teratur, dan terencana dengan tepat. Pemimpin dapat mengembangkan potensi para penyuluh dengan memberikan perhatian yang lebih intensif kepada penyuluh pertanian. Pentingnya memberi penghargaan sesuai prosedur akan membentuk kepuasan kerja yang selanjutnya memperkuat motivasi penyuluh sehingga mereka masih bersedia melakukan pekerjaan mereka sesuai dengan keterampilan dan tujuan yang ingin dicapai oleh organisasi. Keterikatan kerja pada setiap diri dari penyuluh perlu lebih dikembangkan lagi untuk membentuk individu yang berkualitas dan mempunyai motivasi kerja. Harapan tersebut dapat diwujudkan dengan mengembangkan aspekaspek keterikatan kerja agar pandangan dan sikap positif penyuluh terhadap pekerjaan dan organisasi dapat lebih meningkat. Pentingnya meningkatkan pandangan kerja seperti, melakukan pelatihan membuat berbagai bentuk motivasi mengenai etos kerja di semua sudut tempat kerja agar motivasi penyuluh lebih meningkat saat bekerja. Penelitian selanjutnya dapat melibatkan variabel lain yang terkait dengan kinerja penyuluh seperti pelatihan kerja, pendidikan dan masa kerja, kepuasan kerja, komitmen organisasi, dan variabel-variabel lain yang memiliki relevansi. Selain itu juga dapat diterapkan di Kabupaten yang berbeda dengan pengaruh budaya dan kearifan lokal masing-masing daerah. 


\section{REFERENCES}

Andayani, D., S. Kabalmay, R. Resandi, D. Darmawan. (2010). Pemberdayaan Karyawan Berbasis Keunggulan Bersaing, IntiPresindo Pustaka. Bandung.

Arifin, S., R. Mardikaningsih \& Y. R. Al Hakim. (2017). Pengaruh Kedisiplinan, Kompetensi, dan Motivasi Kerja terhadap Kinerja Karyawan, Management \& Accounting Research Journal, 2(1), 43-50.

Arifin, S., Arif R. Putra, C. F. Budi H. (2019). Pengaruh Kompetensi, Kompensasi dan Kepemimpinan terhadap Kinerja Karyawan, Ekonomi, Keuangan, Investasi dan Syariah, 1(1), 23-32.

Babin, B. J., \& J.S. Boles. (1996). The effects of perceived co-worker involvement and supervisor support on service provider role stress, perfor- mance and job satisfaction, Journal of Retailing, 72(1), 57-75.

Bakker, A. B., \& M.P. Leiter. (2010). Work engagement: A handbook of essential theory andresearch. Psychology Press. New York.

Becker, T.E. (1998). Integrity in organizations: beyond honesty and conscientiousness, Academy of Management Review, 23(1), 154-161.

Benson, BJ. (2014). Domain of Competence: Interpersonal and Communication Skills. Academic Pediatrics. 14:S55-S65.

Bitzer, V. (2016). Incentives for enhanced performance of agricultural extension systems. Kit Sustainable Economic Development \& Gender, 6, 1-8.

Buhrmester, D., W. Furman, M.T. Wittenberg \& H.T. Reis. (1988). Five Domains of Interpersonal Competence in Peer Relationship. Journal of Personality and Sosial Psychology, 55(6), 991-1008.

Chakrabartty, S. N. (2013). Best Split-Half and Maximum Reliability. IOSR Journal of Research \& Method in Education, 3(1), 1-8.

Christian, M. S., A.S. Garza \& J.E. Slaughter. (2011). Work engagement: A quantitative review and test of its relations with task and contextual performance. Personnel Psychology, 64(1), 89-136.

Daft, Richard L. (2003). Manajemen Sumber Daya Manusia. Penerbit Erlangga. Jakarta.

Darmawan, D. (2017). Pemberdayaan Kerjasama. Metromedia. Surabaya.

Darmawan, D., M. Hariani, E. A. Sinambela. (2018). Dasar Dasar Manajemen Sumber Daya Manusia. Metromedia. Surabaya.

Darmawan, D., S. Arifin, Arif R. Putra. (2018). Teknik Komunikasi. Metromedia. Surabaya.

Darmawan, D. (2018). Strategi Pengembangan Usahatani Bawang Merah Di Desa Sajen, Kecamatan Pacet, Kabupaten Mojokerto. Jurnal Agrimas, 2(1), 13-22.

Darmawan, D., S. Arifin, R. Mardikaningsih, M. Irfan. (2019). Pengaruh Pendidikan, Kemampuan Kerja dan Pengalaman Kerja terhadap Kinerja Karyawan. Ebis Jurnal Ekonomi Bisnis, 12(1), 35-47.

Darmawan, D., E. A. Sinambela, M. Hariani \& M. Irfan. (2020). Analisis Komitmen Organisasi, Iklim Kerja, Kepuasan Kerja dan Etos Kerja yang Memengaruhi Kinerja Pegawai. Jurnal Bisnis dan Kajian Strategi Manajemen, 4(1), 58-70.

Darmawan, D. et al. 2020. The Quality of Human Resources, Job Performance and Employee Loyalty. International Journal of Psychosocial Rehabilitation, 24(3), 2580-2592.

Darmawan, D. et al. (2021). Tanaman perkebunan prospektif Indonesia. Qiara Media. Surabaya.

Dessler, Gary. (2013). Manajemen Sumber Daya Manusia (Human Resources Management). Gramedia. Jakarta.

Didiza, T. A. (2005). Norms and Standards for Extension and Advisory Services in Agriculture. Masiphula Mbongwa, DirectorGeneral: Department of Agriculture.

Djati, S. Pantja \& D. Darmawan. (2005). Pengaruh Kinerja Karyawan terhadap Kepuasan, Kepercayaan, dan Kesetiaan Pelanggan. Jurnal Manajemen dan Kewirausahaan, 7(1), 48-59.

Dubinsky, A. J., R.D. Howell, T.N. Ingram \& D.N. Bellenger. (1986). Salesforce Socialization. Journal of Marketing., 50(4), 192-207.

Furiady O, Kurnia R. (2015). The effect of work experiences, competency, motivation, accountability and objectivity towards audit quality. Procedia -Social and Behavioral Sciences, 328-35

Gibson, J.L., J.M. Ivancevich \& Donelly. (2011). Organization: Structure, Process, Behavior. Business Publication. Dallas.

Guchait, P, T. Simons \& A. Pasamehmetoglu. (2016). Error recovery performance: The impact of leader behavioral integrity and job satisfaction. Cornell Hospitality Quarterly, 57(2), 150-161.

Hariani, M. (2017). Analisis Respon Pekerja terhadap Pemberdayaan Sumber Daya Manusia di Bagian Pengendalian Kualitas dalam Kegiatan Ekspor Hasil Produksi Rotan. Jurnal Agrimas, 1(1), 19-28.

Hariani, M., S. Arifin, Arif R. Putra. (2019). Pengaruh Iklim Organisasi, Pengalaman Kerja dan Motivasi Kerja terhadap Komitmen Kerja Karyawan. Management \& Accounting Research Journal, 3(2), 22-28.

Hair, J. F. Jr., C.B. William, B.J. Banin \& R.E. Anderson. (2010). Multivariate Data Analysis, 7th editionUpper Saddle RiverPrentice Hall. . New Jersey.

Hutomo, Sanjaya. \& D. Darmawan. (2011). Optimalisasi Manajemen Sumber Daya Manusia Menuju Keunggulan Bersaing. Jurnal Ilmu Sosial, 5(1), 13-22.

Kahn, W.A. (1990). Psychological conditions of personal engagement and disengagement at work. Academy of Management Journal, 33(4), 692- 724.

Karina, Ana., Toni Baskoro K. \& D. Darmawan. (2012). Pengantar Psikologi. Addar Press. Jakarta

Khasanah, Hikmahtul, Setya Arum \& D. Darmawan. (2010). Pengantar Manajemen Bisnis. Spektrum Nusa Press. Jakarta.

Kotur, R. B. \& S. Anbazhagan. (2014). Education and Work-Experience - Influence on the Performance. IOSR Journal of Business and Management (IOSR-JBM), 16(5), 104-110.

Luthans, Fred. (2007). Organizational Behavior. Irwin/McGraw-Hill. New York.

Marcus, B. \& H. Schuler. (2004). Antecedents of counterproductive Behavior at Work: A General Perspective. Applied J. Psychol, 89(4), 647- 660.

Mardikaningsih, R. (2014). Kinerja Karyawan dan Faktor-Faktor yang memengaruhinya. Jurnal Ilmu Sosial, 7(2), 73-84.

Mardikaningsih, R. (2016). Variabel Kepemimpinan dan Lingkungan Kerja serta Pengaruhnya terhadap Kinerja Karyawan. Management \& Accounting Research Journal, 1(1), 55-62. 
Mardikaningsih, R., S. Arifin, Arif R. Putra, \& M. Hariani. (2017). The Effect of Motivation and Work Commitment on The Performance of Agricultural Extension Agents. Jurnal Agrimas, 1(2), 115-124.

Mardikaningsih, R. (2019). Pengembangan Kinerja Penyuluh Pertanian Melalui Keterampilan Interpersonal dan Etos Kerja. Jurnal Agrimas, 3(2), 59-68.

Martin, G.S., M.A. Keating, C.J. Resick, E. Szabo, H.K. Kwan \& C. Peng. (2013). The meaning of leader integrity: a comparative study across Anglo, Asian, and Germanic cultures. The Leadership Quarterly, 24(3), 445-461.

Nusbuga, Y. K. (2009). Analysis of Leadership Styles and School Performance of Secondary Schools in Uganda, Doctoral thesis. Port Elizabeth: Department of Education, Nelson Mandela Metropolitan University. Uganda.

Pallant, J. (2011). A Step by Step Guide to Data Analysis Using the SPSS Program: Survival Manual, (4th Ed.). McGraw-Hill. Berkshire.

Palanski, M.E. \& F.J. Yammarino. (2009). Integrity and leadership: a multi-level conceptual framework. Leadership Quarterly, 20(3), 405-420.

Palembeta, Thoriq \& S. Arifin. (2014). Pengaruh Penilaian Kinerja terhadap Motivasi Kerja. Jurnal Ilmiah Manajemen Pendidikan Indonesia, 1(1), 23-32.

Paloniemi, S. (2006). Experience, competence and workplace learning. Journal of workplace learning, 18(7/8), 439-450.

Putra, Arif R., D. Darmawan \& E. A. Sinambela. (2017). Pengawasan dan Koordinasi Kerja serta Pengaruhnya terhadap Produktivitas Kerja Karyawan. Akuntabilitas Jurnal Ilmiah Ilmu-ilmu Ekonomi, 10(2), 12-24.

Putra, Arif R., E. Retnowati \& E. A. Sinambela. (2019). Pengaruh Komunikasi Kerja dan Integritas terhadap Kinerja Pegawai. Ebis, Jurnal Ekonomi Bisnis, 12(1), 23-34.

Rhoades, L., \& R. Eisenberger. (2002). Perceived organizational support: A review of the Literature. Journal of Applied Psychology, 87(4), 698-714.

Robbins, S., \& Timothy A. J. (2008). Perilaku Organisasi, Organizational Behaviour. Gramedia. Jakarta.

Roos, G., A. Bainbridge \& K. Jacobsen. (2001). Intellectual Capital Analysis as a Strategic Tool, International Capital Services (ICS) ltd. London. United Kingdom. Strategy and Leadership Journal, 29(4), 21-26.

Santosa, Aditya \& D. Darmawan. (2002). Hubungan Kepemimpinan, Budaya Organisasi dan Kinerja Karyawan. Jurnal Ilmu Manajemen, 3(2), 81-92.

Sato, Kaori., M. Nakamuro \& H. Owan. (2019). The Effect of Interpersonal Skills on Worker Performance, RIETI Discussion Paper Series 19-E-045. 1-29.

Schaufeli, W. B., \& A.B. \& Bakker. (2001). Werk en welbevinden: Naareen positieve benadering in de Arbeids-en Gezondheidspsychologie [Work and well-being: Towards a positive approach in Occupational Health Psychology]". Gedrag \& Organisatie. 14, 229-253.

Simons, T. (2002). Behavioral integrity: The perceived alignment between manager words and deeds as a research focus. Organization Science, 13(1), 18-35.

Sinambela, E. A. (2014). Pengaruh Motivasi, Disiplin dan Lingkungan Kerja terhadap Kepuasan dan Loyailtas Kerja. Jurnal Ilmu Sosial, 7(3), 123-136.

Sinambela, E. A., R. Mardikaningsih, S. Arifin, H.D. Ayu. (2020). Development of Self Competence and Supervision to Achieve Professionalism. Journal of Islamic Economics Perspectives, 1(2), 33-42.

Singh, I. A. K. 2014. Role of Interpersonal Communication in Organizational Effectiveness. International Journal of Research in Management and Business Studies. Vol.1, No.4, 36-39.

Sjamsi, Nurul \& D. Darmawan. (2004). Peran Strategis Layanan pada Penyelenggaraan Pelayanan Publik. Jurnal Administrasi Publik, 1(1), 83-95.

Suvedi, M., S. Campo \& M.K. Lpinski. (1999). Trends in Michigan farmers' information seeking behaviors and perspective on the delivery of information. Journal of Applied Communications, 83 (3), 33-50.

Syahrudin, Husni. (2018). The Effect of Interpersonal Skills on Performance of Regional Secretariat Employees in Kapuas Hulu Regency. Jurnal Terapan Manajemen dan Bisnis, 4(2), 192-201.

Valero D, Hirschi A. (2016). Latent profiles of work motivation in adolescents in relation to work expectations, goal engagement, and changes in work experiences. Journal of Vocational Behavior, 93, 67-80.

Van den Ban, A.W. \& H.S. Hawkins. (1996). Agricultural extension. 2nd ed. Blackwell Science Pty Ltd. Victoria.

Wahyudi, Ikhsan., D. Bhaskara, D. Darmawan, Hermawan \& N. Damayanti. (2006). Kinerja Organisasi dan Faktor-Faktor Pembentuknya. Jurnal Ekonomi dan Bisnis, 4(2), 95-108.

Werdati, Fauchil., D. Darmawan \& N. R. Solihah. (2020). The Role of Remuneration Contribution and Social Support in Organizational Life to Build Work Engagement. Journal of Islamic Economics Perspectives, 1(2), 20-32.

Weiss, A., L. Van Crowder \& M. Bernardi. (2000). Communicating agrometeorological information to farming communities. Agricultural and Forest Meteorology, 103, 185-196. 